\title{
No Proof that Biofilm Bacteria are Causing Dermal Filler Granulomas
}

\author{
Lemperle Gottfried* \\ Division of Plastic Surgery, University of California, USA \\ *Corresponding author: Lemperle Gottfried, Division of Plastic Surgery, University of California, San Diego, USA \\ To Cite This Article: Lemperle Gottfried, No Proof that Biofilm Bacteria are Causing Dermal Filler Granulomas. Am J Biomed Sci \& Res. 2019 - \\ 4(1). AJBSR.MS.ID.000749. DOI: 10.34297/AJBSR.2019.04.000749
}

Received: July 02, 2019 | Published: July 15, 2019

\begin{abstract}
An estimated 1000 patients worldwide, who develop foreign body granulomas after the injection of all kinds of dermal fillers, are treated falsely with systemic antibiotics over several months - just because one pathologist claimed to have found the reason for granulomas in a local bacterial infection. The problem is the easiness today how authors can find, copy, and refer to articles, whose results they never questioned but cited, only. One copies the results from the other - and by the way of repeating a hypothesis several times, it becomes the truth for the majority of a whole community of dermatologists and aesthetic surgeons.
\end{abstract}

Since its first publication in 2005 [1] a multitude of at least 30 publications [2] offer broad-spectrum antibiotics as the treatment of choice for dermal filler granulomas. One reason is the widespread fear of injecting corticosteroids locally because the possibility of causing skin atrophy if injected outside the granuloma. If corticosteroid crystals (triamcinolone, prednisolone, betamethasone), the logical and effective treatment of choice $[3,4]$, are injected strictly intralesional by moving the needle back and forth within the nodule, skin atrophy will never occur. The second reason for bacteria is causing granulomas is appealing because it blames the patient and excludes the product and its injector.

\section{Introduction}

\section{Foreign body granulomas}

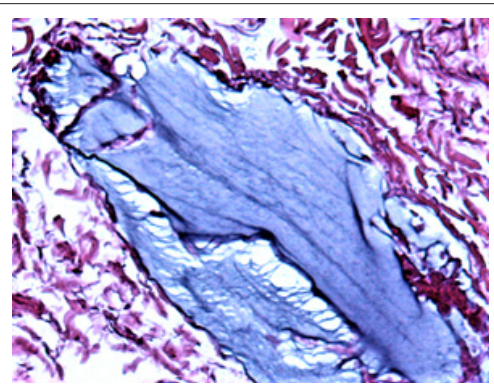

Figure 1a: Normal Aquamid implant at one month with scattered cells surrounding the biocompatible and inert gel.

According to the American Society for Aesthetic Plastic Surgery (ASAPS) approximately 2 million dermal filler treatments are performed every year with $>160$ products from $>50$ companies. The late complication rate consisting mainly of chronic inflammation or foreign body granuloma (FBG) formation ranges between 1 per 1000 and 2000 injected patients [5]. FBGs occur several months to years after injection at all implantation sites at the same time. Histologically, the granulomas are infiltrated by many macrophages and giant cells, fibroblasts and collagen fibers but few inflammatory cells (Figures 1a \& 1b). Without treatment, they may grow to the size of beans, remain virtually unchanged for some months or years, and then resolve spontaneously. Permanent implants are not characterized by a higher rate of FBG per se than temporary implants; however, their clinical appearance is more pronounced and their persistence much longer $[5,6]$ if not treated adequately.

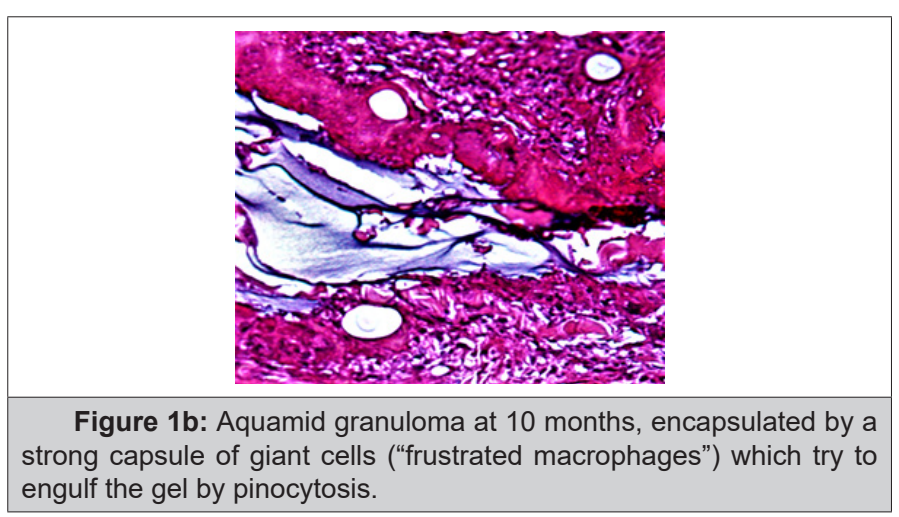

The origin, reason or cause of FBGs are still unknown but sudden systemic bacterial infections have been suggested as trigger 
of foreign body granulomas [5]. Permanent injectables like fluid silicone, PMMA-microspheres (Artecoll $®$, Bellafill $\AA$, Metaderm ${ }^{\text {TM }}$, Linnea safe $\AA$, Biosimetric $₫$, and polyacrylamide gel (Aquamid $₫$ ) (Figs. 2a and 2b) can develop serious sclerosing or cystic granulomas after years, whereas slowly absorbable injectables like polylactic acid (Sculptra ${ }^{\circledR}$ )- or calcium apatite microspheres (Radiesse ${ }^{\circledR}$ cause fewer granulomas within one to 3 years after injection. The different faster absorbed hyaluronic acid gels (Restylane®, Juvederm $\AA$, Belotero $\AA$, Teosyal $\AA$ ) form approximately the same number of granulomas within 6 to 24 months after injection. They appear as sterile cystic granulomas (Figures 2a \& 2b), which last for 3 to 6 months until tissue hyaluronidases have dissolved the last residue of hyaluronic acids, and macrophages have phagocytosed their own foreign body cells.

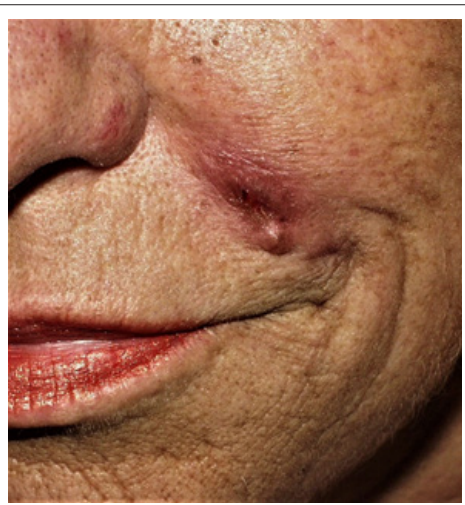

Figure 2a: Cystic Restylane granuloma in both nasolabial folds 8 months after injection.

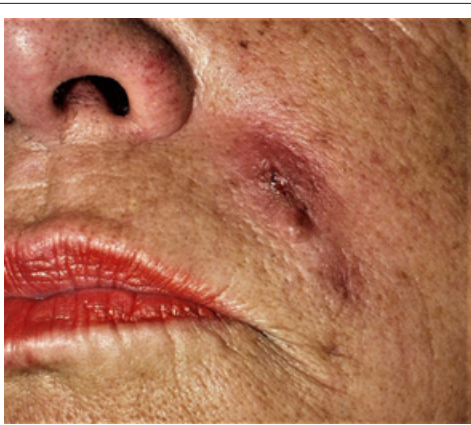

Figure 2b: Two days later after spontaneous opening. The healing took 4 months but could have been accelerated by intralesional triamcinolone injections.

On both sides of the debate surrounding absorbable versus nonabsorbable fillers, the medical community has adherents of almost religious-like fervor. One fact, however, is undisputable: the deeper the implants are injected, the less is the possibility of FBG formation [7]. The dermis by far is the organ most sensitive and prone to immunological (cellular) and allergic (by antibodies) reactions. Therefore, epiperiosteal or subdermal injections into the dermal-subdermal junction will cause far fewer FBG than intradermal injections [7].

\section{Biofilm as cause of granulomas?}

The attention, the biofilm 'hypothesis' received as a cause of late inflammation and even granuloma formation after injection of dermal fillers, is quite amazing [8-10]. Two interesting and critical articles $[11,12]$ perfectly describe the nature of biofilms but adopt this concept for injectable fillers as well. In our age of evidencebased-medicine and peer reviewed journals, our primary goal should focus on the proof of all postulated "facts" in a manuscript.

There is no doubt that fluid injectables like fluid silicone or polyacrylamide (Aquamid) can be infected by bacteria from the blood stream in patients with decreased host resistance many years after injection - often with Propionibacterium acnes [13].

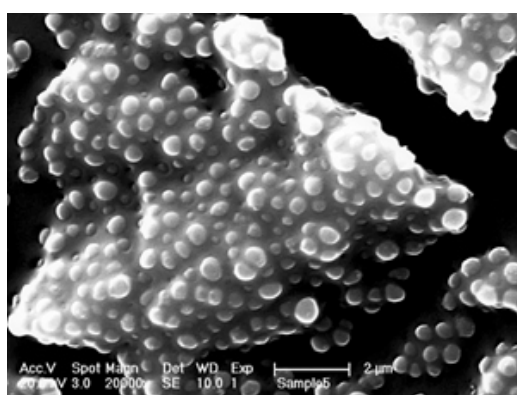

Figure 3a: The biofilm of methicillin-resistant staphylococcus aureus (MRSA) protects its containing bacteria from disinfectants, antibiotics, and leucocytes and macrophages.

The role of biofilm infections is undisputable on inert surfaces such as teeth, catheters, breast implants, and artificial hip and knee joints (Figure 3a). The well-known capsule formation after breast augmentation is the result of such an infection on the surface of silicone implants, for example $[14,15]$. Certain bacteria in exudates settle from a free floating ("planktonic") state to a smooth artificial or natural surface and develop a self-protective biofilm against disinfectants, antibiotics and macrophages - and this can happen as early as day one (Figure $3 \mathrm{~b}$ ).

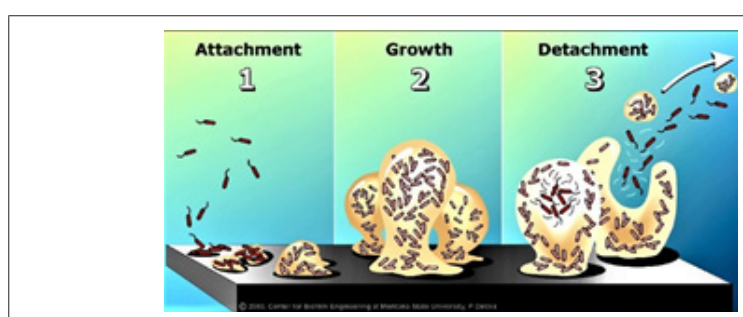

Figure 3b: $90 \%$ of all bacteria form a biofilm when they hit a smooth surface. Usually, they die from malnutrition after a few months, but some are constantly growing and are releasing "planktonic" bacteria, which then can be detected by bacteriology. (from Center for Biofilm Engineering, Montana State University, 2003)

So far, it is not known whether these bacteria can stick to an irregular surface of injected fluid droplets, particles, microspheres, or tissue-gel-junctions. All injectable foreign materials stimulate an initial local edema to facilitate cell- and especially macrophage invasion but cause no local fluid accumulation (as do breast implants), in which bacteria could multiply and settle.

Polyacrylamide fillers were used since 1980 in high volumes in the former Soviet Union and Asia under the name of Formacryl ${ }^{\circledR}$ and Interfall ${ }^{\circledR}$ as an answer to the American injectable fluid silicone. Early in the 21st century, Russia, Ukraine, and China banned injectable polyacrylamides because of dislocation and a high number of cystic granulomas [5]. Bacterial infections were 
rarely a proven cause. The same was true for Bio-Alcamid® from Italy, which was accompanied with a number of "late infections" and "sterile abscesses", which were cystic granulomas in reality How could one explain an infectious cause, if most of the sterile abscesses occur on both sides of the face at the same time? (Figure $4 a \& 4 b)$.

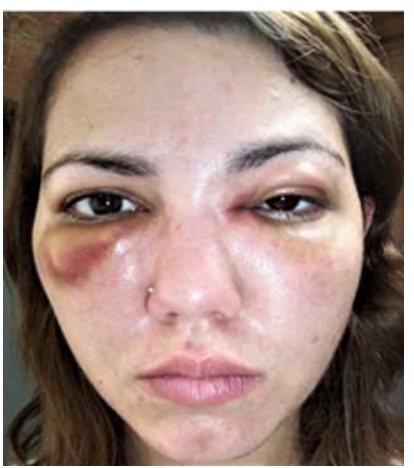

Figure 4a: Cystic Acrylamide granuloma 2,5 years after injection and 2 days after onset at the same time on both sides (Courtesy of Dr. Ignacio Puiggros, Barcelona)

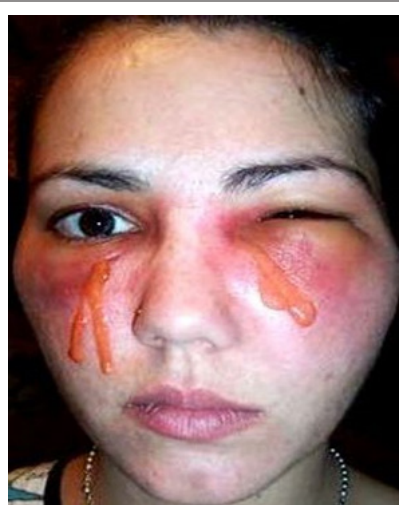

Figure 4b: Stab incisions 2 days later reveal a "sterile abscess" without bacterial growth. Healing took 7 months because the whole giant cell wall had not been removed but was left to phagocytosis.

Results

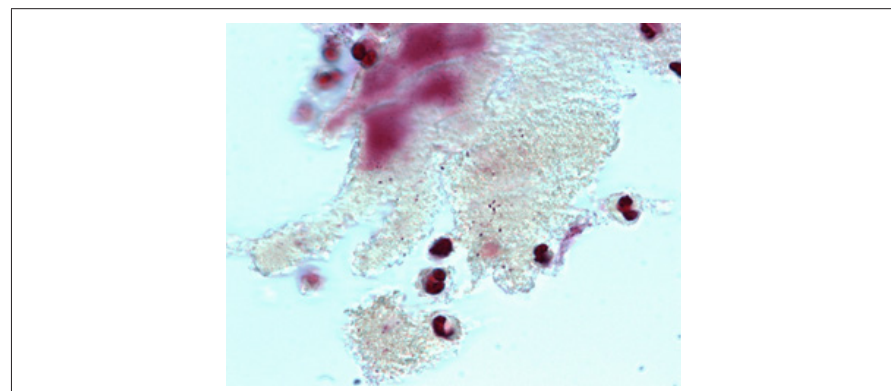

Figure 5a: These few bacteria detected on the surface of a histological slide of Aquamid gel were considered proof of bacteria being the cause of cystic Aquamid granulomas [1].

In an effort to avoid the name granuloma for late complications after the injection of Aquamid®, another polyacrylamide gel from Denmark, the idea was born to rather blame bacteria and call it a 'biofilm' infection [1,16-18,22-24], which sounds less dangerous to physicians and patients (Figure 5a \& 5b). Admittedly, the nomenclature of late inflammatory events after filler injections is far from uniformly or fully understood $[5,16]$ but is based on personal thoughts more than on facts.

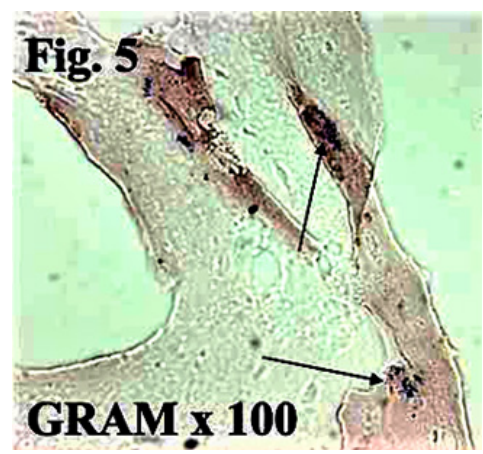

Figure 5b: Bacteria in the tissue without attacking granulocytes are more suspicious of air born bacteria landing on the surface of this probe [1].

The first published "proof" of a biofilm was the following list of bacteria recovered from histological slides in a pathology laboratory [1]. Most physicians have never heard of these exotic strains, which our bacteriologist suspected to be air born bacteria in a laboratory [19] but never found multiplying in a human body:

a. The PCR/DNA identification showed:

b. Sphingomonas species

c. Burkholderi cepacia,

d. Paenibacillus favisporus

e. Bosea species,

f. Paenibacillus xyanilyticum

g. Paenibacillus pabuli

h. glacial ice bacterium

i. and a single bacterium Streptococcus viridans,

j. Shigella species,

k. Mesorhixobium species,

l. Paenibacillus favisporus

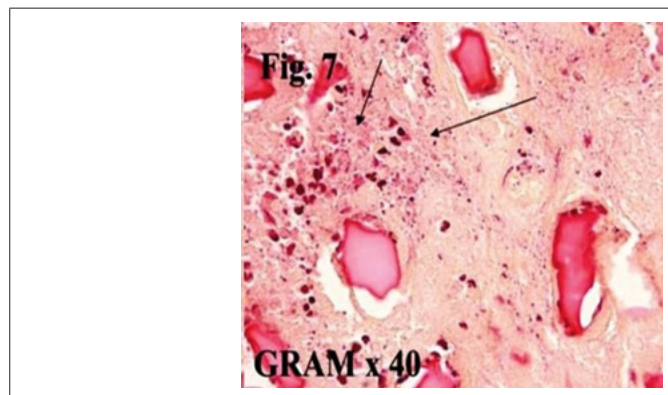

Figure 6a: Some clusters of granulocytes may suggest phagocytized bacteria but are no proof for their possible cause in granulomas [1].

The second "proof" was a slide with approximately 20 Grampositive cocci [17] scattered on a line in non-reactive tissue but not on the surface of the surrounding Aquamid droplets. If these 
bacteria would have multiplied in living tissue, at least some typical mononuclear cells would have shown up. On other parts of the slides, granulocytes were detected (Figure 6a \& 6b). All initially accused bacterial strains are not found on human skin but must be air borne bacteria, most probably.

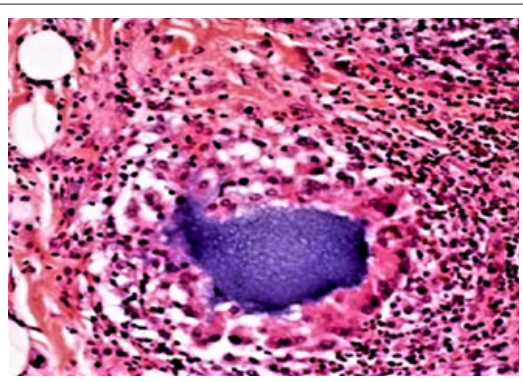

Figure 6b: Aquamid granuloma: with giant cell wall

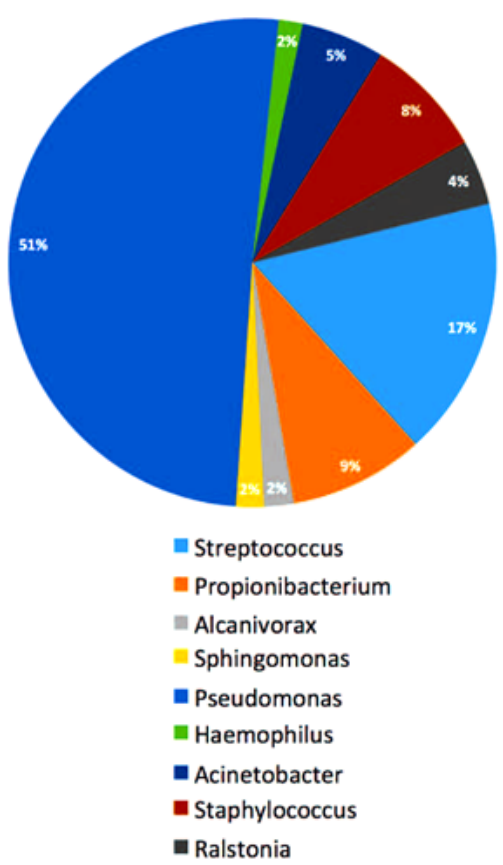

Figure 7a: Bacteria found in 5 probes of different filler granulomas [20]: bacteria are all over our body, but these are still no proof that they cause filler granulomas.

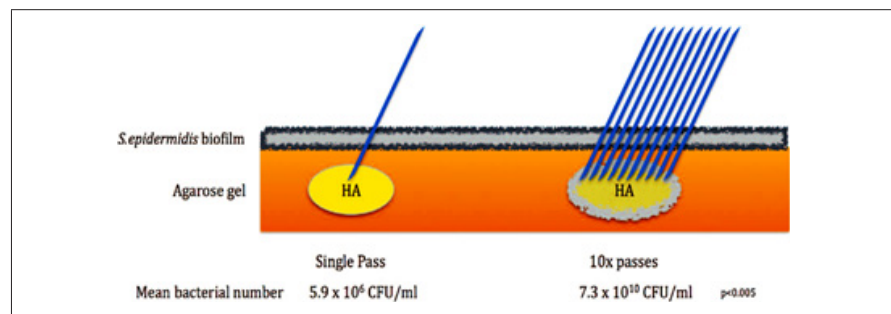

Figure $7 \mathrm{~b}$ : Multiple needle stitches bring more bacteria beneath the skin - but all are phagocytized immediately by a healthy defense system [20].

Even a recent article from Australia [20], which tried to support the Danish article of 2009 [17], retrieves all kinds of clinically known bacteria as reason for 5 clinically different filler granulomas (Figure 7a). Transdermal needle stitches bring always bacteria beneath the skin (Figure $7 \mathrm{~b}$ ) but ubiquitous mononuclear cells and macrophages will phagocytose all invading bacteria immediately.

\section{Discussion}

The consequent disaster for patients with granulomas is that uncritical colleagues believe in this unproven hypothesis of an infectious origin -and treat these patients with antibiotics over months - instead with proven high doses of corticosteroids once or twice [3].

The proof of such a conclusion is not the detection of a few bacteria on histological slides and identifying them, but to demonstrate a "biofilm" with hundreds of biofilm bacteria in the wall of a "sterile abscess", for example. We encourage all colleagues not only to drain the next "sterile abscess" [20] (Figure 2) but to remove the abscess wall as recommended [5] and send it to bacteriology with the stipulation to search for biofilm bacteria (with ultrasound sonication and electron microscopy). If they detect a living colony of biofilm with hundreds of bacteria (as it is found on infected shells of silicone implants [15] such a picture will convince the filler community, but not these few exotic bacteria from two pathology and bacteriology labs.

Whether a local bacterial infection $[20,21]$ or a systemic bacterial infection [5] can be the cause of delayed granulomas [12] remains the question. Until its proof, the present recommendation of antibiotic treatment [16-18] instead of corticosteroid injections [3] of cystic and sclerosing granulomas should remain a hypothesis. For the best of our patients, we must treat them with proven medications $[3,4,22]$ - and not delay the treatment for months with unproven antibiotics, who do not penetrate biofilm covered bacteria at all.

\section{Conclusion}

\section{The Facts}

a. There is no doubt that skin bacteria are brought with every injection through the skin [20] as they are found in every open surgical wound. The skin can never be 100 percent "sterilized": further abraded skin scales by raw surgical gloves, and sebaceous and sweat glands remain a reservoir of nonpathogenic bacteria (Figure 8a).

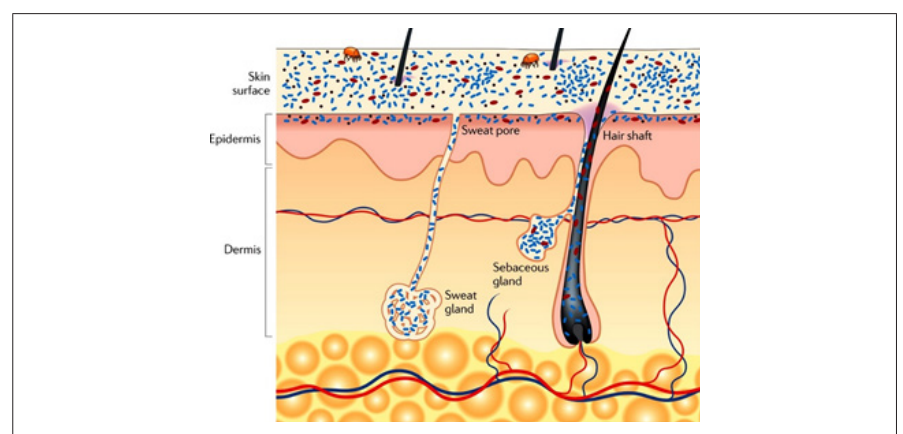

Figure 8a: Our individual skin bacteria and our gut bacteria (microbiome) protect us from foreign invaders. However, they can be unbalanced by uncritical antibiotic administration and may lead to so far unknown disorders.

b. Immediate infections after filler injections occur extremely seldom because the ubiquitous body's defense system with its armada of leucocytes and macrophages phagocytizes invading single bacteria immediately. 
c. Without a healthy cellular defense, these suddenly intradermal bacteria would cause a local infection or abscess after each needle stitch.

d. Bacteria grow on hyaluronic acid, silicone and acrylamide fillers but cause extremely seldom an infection or abscess within the first weeks after injection.

e. On the other hand, foreign body granulomas after hyaluronic acid fillers occur 3 to 6 months after injection; sclerosing granulomas after particulate fillers after several years [3].

f. The natural regression time of hyaluronic acid granulomas without special treatment is three to nine months, the natural regression of granulomas after particulate products like Sculptra, PMMA [6] or Radiesse without treatment is one to three years [3].

g. The histological characteristics of typical filler granulomas are macrophages and foreign body giant cells [3], which will not tolerate the growth of single bacteria in their surroundings.

h. Under the present treatment of choice (intralesional triamcinolone in high doses!), the regression of filler granulomas starts after 2 weeks and may be finished after another two or three injections in a 4-weeks sequence [3].

i. The effect of the recommended long-term antibiotic therapy starts after months, the same time hyaluronic acid granulomas heal by themselves.

\section{The Hypothesis of Bacterial Infection}

a. Bacteria are brought into the skin with each needle stitch [20].

b. Bacteria in small numbers have been detected on histological slides of polyacrylamide (Aquamid) filler gel $[17,18]$ and in different filler granulomas, too [20].

c. These few scattered and exotic bacteria are assumed to be the cause of late granuloma formation.

d. Clusters of granulocytes have been detected in histological slides and described as proof of bacterial infection [17].

e. The fact that the content of "cystic granulomas" [3] (Figure 2a \& 2b) is most often sterile [3,21] are the base of the assumption that so-called "biofilms" must be involved, which rarely allow the detection of free "planktonic" bacteria.

f. Biofilms can be formed on open wounds and smooth surfaces of implants by a majority of bacterial strains $[8,9]$ (Figure 7b).

g. Therefore, broad spectrum antibiotics are recommended as treatment and prophylaxis of choice for all filler granulomas [22-24].

h. A human body contains billions of "sleeping bacteria", which may suddenly "awake" and multiply.

i. If bacteria would be involved in granuloma formation which occurs many months or even years later - the argument of "bacteria brought in with each needle stitch" [20] is not convincing.

\section{Summary}

a. A reason for this widespread acceptance is the inborn fear of dermatologists to cause skin atrophy with intralesional injected corticosteroids, which can occur only if injected outside of the granuloma nodules.

b. The second reason is the complained ineffectiveness of systemic are locally applied corticosteroids, which is always based on too low doses injected $[3,25]$.

c. If bacteria would be the cause of granulomas, how can one explain the immediate effect of intralesional corticosteroids, which are known to suppress host defenses and rather support bacterial infections?

d. A biofilm consists of bacteria, which multiply under a mucous slime consisting of polysaccharides and other polymers. This slime occurs already in the first days and protects the biofilm bacteria from disinfectants, antibiotics, and from phagocytosis by leucocytes and macrophages.

e. If the proposed broad-spectrum antibiotics would be effective, the granulomas should regress immediately - and not after several months.

f. The proof that bacteria are interfering with injected fillers and causing possible granulomas can only be expected from a high number of standardized probes from filler granulomas. These occur so seldom (1:2000 patients) that only a professional organization of injectors could manage this task.

g. Unfortunately, hundreds of patients, who developed granulomas after filler injections, are treated with antibiotics for months in vain until natural regression occurs [23]. Granuloma formation is a hyper-immunological reaction which must be decreased with high doses of intralesional crystal steroids [3]. - apart from the possibility of developing antibiotic-resistant bacterial strains in the microbiome of these patients.

\section{References}

1. Christensen L, Breiting V, Janssen M, Vuust J, Hogdall E (2005) Adverse reactions to injectable soft tissue permanent fillers. Aesthetic Plast Surg 29(1): 34-48.

2. Ibrahim 0, Overman J, Arndt KA, Dover JS (2018) Filler nodules: Inflammatory or infectious? A review of biofilms and their implications on clinical practice. Dermatol Surg 44(1): 53-60.

3. Lemperle G, Gauthier-Hazan N (2009) Foreign body granulomas after all injectable dermal fillers. Part 2: Treatment options. Plast Reconstr Surg 123(6): 1864-1876

4. Gandy J, Bierman D, Zachary C (2017) Granulomatous reaction to Belotero Balance: A case study. J Cosmet Laser Ther 19(5): 307-309.

5. Lemperle G, Gauthier-Hazan N, Wolters M, Eisemann-Klein M, Zimmermann U, et al. (2009) Foreign body granulomas after all injectable dermal fillers. Part 1: Possible causes. Plast Reconstr Surg 123(6): 1842-1863.

6. Gelfer A, Carruthers A, Carruthers J, Jang F, Bernstein SC (2007) The natural history of polymethylmethacrylate microspheres granulomas. Dermatol Surg 33(5): 614-620. 
7. Li D, Luo SK, Wang YC, Lemperle G (2017) Facial volume restoration with permanent dermal filler (Artecoll-4) in Chinese women. Facial Plast Surg 33(5): 537-544.

8. Sadashivaiah AB, Mysore V (2010) Biofilms: their role in dermal fillers. J Cutan Aesthet Surg 3(1): 20-22.

9. Hassid VJ, Monheit G, Nguyen AT, Brown SA, Fagien S (2010) Soft-tissue filler complications: The important role of biofilms. Plast Reconstr Surg 126(4):1801-1802.

10. Nguyen A, Rohrich RJ, Fagien S (2010) Reply. Plast Reconstr Surg 126 1802.

11. Monheit GD, Rohrich RJ (2009) The nature of long-term fillers and the risk of complications. Dermatol Surg 35(2): 1598-1604.

12. Rohrich RJ, Monheit G, Nguyen AT, Brown SA, Fagien S (2010) Soft-tissue filler complications: The important role of biofilms. Plast Reconstr Surg 125(4): 1250-1256.

13. Jessop ZM, Welck M, Zinser E, Garlick N, Hopkins S (2018) Late presentation of infected silicone granulomas in the lower limb. Clin Med Insights Arthritis Musculoskelet Disord 22(11): 1179544118759020.

14. Burkhardt BR, Dempsey PD, Schnur PL, Tofield JJ (1986) Capsular contracture: a prospective study of the effect of local antibacterial agents. Plast Reconstr Surg 77(6): 919-932.

15. Tamboto H, Vickery K, Deva AK (2010) Subclinical (biofilm) infection causes capsular contracture in a porcine model following augmentation mammaplasty. Plast Reconstr Surg 126(3): 835-842.

16. Christensen L (2007) Normal and pathologic tissue reactions to soft tissue gel fillers. Dermatol Surg 33(2): S168-S175.

17. Bjarnsholt T, Tolker-Nielsen T, Givskov M, Janssen M, Christensen LH (2009) Detection of bacteria by fluorescence in situ hybridization in culture-negative soft tissue filler lesions. Dermatol Surg 35(2): 16201624

18. Christensen LH (2009) Host tissue interaction, fate, and risks of degradable and nondegradable gel fillers. Dermatol Surg 35(2): 1612 1619.

19. Lemperle G, Nicolau P, Scheiermann N (2011) Is there any evidence for biofilms in dermal fillers? Plast Reconstr Surg 128(2): 84e-85e.

20. Saththianathan M, Johani K, Taylor A, Hu H, Vickery K, et al. (2017) The role of bacterial biofilm in adverse soft-tissue filler reactions: A combined laboratory and clinical study. Plast Reconstr Surg 139(3): 613-621.

21. Seok J, Jang YJ, Li K, Mun SK, Kim BJ (2016) Streptococcus sanguinis isolated from filler granuloma: Successful treatment with incision and drainage. Dermatol Ther 29(6): 463-465.

22. Christensen L, Breiting V, Bjarnsholt T Bac, Pallua N, Zaat SA, et al (2013) Bacterial infection as a likely cause of adverse reactions to polyacrylamide hydrogel fillers in cosmetic surgery. Clin Infect Dis 56(10): 1438-1444

23. Nygart JF, Nygart VA, Borggren M, Tvede M (2014) Effect of prophylactic antibiotics on polyacrylamide gel safety in facial augmentation. J Drugs Dermatol 13(5): 571-573.

24. Alhede M, Er Ö, Eickhardt S, Kragh K, Alhede M, et al. (2014) Bacterial Biofilm formation and treatment in soft tissue fillers. Pathog Dis 70(3): 339-346.

25. Urdiales Gálvez F, Delgado NE, Figueiredo V, Mira M, Moreno A, et al. (2018) Treatment of soft tissue filler complications: Expert consensus recommendations. Aesthetic Plast Surg 42(2): 498-510. 